\title{
BMJ Open A cross-sectional study of bacterial vaginosis, intravaginal practices and HIV genital shedding; implications for HIV transmission and women's health
}

\author{
Maria L Alcaide, ${ }^{1}$ Maureen Chisembele, ${ }^{2}$ Emeria Malupande,${ }^{2}$ Kristopher Arheart, ${ }^{3}$ \\ Margaret Fischl, ${ }^{1}$ Deborah L Jones ${ }^{4}$
}

To cite: Alcaide ML, Chisembele M, Malupande E, et al. A cross-sectional study of bacterial vaginosis, intravaginal practices and HIV genital shedding; implications for HIV transmission and women's health. BMJ Open 2015:5:e009036.

doi:10.1136/bmjopen-2015009036

- Prepublication history for this paper is available online. To view these files please visit the journal online (http://dx.doi.org/10.1136/ bmjopen-2015-009036).

Received 10 June 2015 Revised 16 September 2015 Accepted 5 October 2015

CrossMark

For numbered affiliations see end of article.

Correspondence to Dr Maria L Alcaide; malcaide@med.miami.edu

\section{ABSTRACT}

Objectives: Bacterial vaginosis (BV) is associated with an increased risk of HIV transmission, and intravaginal practices (IVP) are an important risk factor for developing BV. The relationship between IVP, BV and HIV lower genital shedding, responsible for HIV transmission, has not been examined in women receiving antiretrovirals in Zambia.

Design: Cross-sectional study.

Setting: Community Health Center in Lusaka, Zambia. Participants and methods: Participants were HIVinfected women receiving antiretroviral therapy and engaging in IVP $(n=128)$. Participants completed audio computer-administered self-interviews to assess IVP and underwent a vaginal examination. BV was diagnosed using Nugent criteria. HIV-1 lower genital shedding was assessed by measuring HIV-1 RNA in cervicovaginal lavages.

Results: Most women engaged in IVP daily (114, $89.0 \%)$ and $81(63.3 \%)$ of the participants had BV. HIV-1 genital shedding was detected in $18(14.2 \%)$ participants. BV was associated with daily use of IVP (prevalence ratio, $\mathrm{PR}=4.58, \mathrm{Cl} 1.26$ to $16.64, \mathrm{p}=0.02$ ) and weekly use of traditional medicines for IVP $(P R=1.33, \mathrm{Cl} 1.05$ to $1.68, p=0.02)$. The only factor associated with HIV-1 lower genital shedding was plasma viraemia ( $P R=4.61, \mathrm{Cl} 2.02$ to 10.54, $\mathrm{p}<0.001$ ). Neither IVP nor BV were associated with HIV shedding. Conclusions: Despite the frequency of IVP and high prevalence of BV, plasma viraemia was the primary factor associated with HIV lower genital shedding. These findings support early initiation of antiretrovirals as an HIV prevention tool. Given adverse health outcomes associated with BV, the association between frequent IVP and BV, and the powerful local norms and traditions encouraging IVP, there is a need for studies assessing culturally tailored interventions to decrease $\mathrm{BV}$ in high-prevalence settings.

\section{INTRODUCTION}

Bacterial vaginosis (BV) is the most common genital infection in women and occurs in up to $50 \%$ of women with HIV infection. ${ }^{1-3} \mathrm{BV}$

\section{Strengths and limitations of this study}

- This is one of the few studies evaluating the relationship between intravaginal practices (IVP), bacterial vaginosis (BV) and HIV lower genital shedding in HIV-infected women receiving antiretroviral therapy.

- Despite high rates of IVP and BV, our findings confirm that plasma viraemia is the primary factor associated with HIV lower genital shedding and support early initiation of antiretroviral treatment as an HIV prevention tool. However, given the strong association with frequent IVP and BV, IVP interventions to decrease BV should be evaluated as part of women's health programmes.

- Our main limitation is that most women reported daily IVP and this was compared with women who reported less frequent IVP. Owing to the close relationship between daily use of the different products (cloth, soap and water), and to avoid collinearity, only daily use of IVP was included in the multivariable model.

is characterised by a vaginal discharge with fishy odour, a shift in vaginal $\mathrm{pH}$, loss of vaginal lactobacilli and increase in Gram-negative anaerobic bacteria. BV has important associations with adverse health outcomes such as an increased risk of preterm delivery, spontaneous abortion and complications of gynaecological surgeries. ${ }^{1}{ }^{4}$ $\mathrm{BV}$ is also associated with an increased risk of acquisition and transmission of sexually transmitted infections (STI), and HIV, to sexual partners and new borns. ${ }^{5-10}$

The aetiology of BV is controversial and remains largely unknown. Epidemiological and clinical studies have found associations of BV with intravaginal cleansing, new sexual partners, multiple sex partners and unprotected vaginal intercourse; but it has also been suggested that BV may be caused by a sexually transmitted pathogen. ${ }^{11-13} \mathrm{BV}$, 
however, can occur in women who are not sexually active, and one of the main risks for developing $\mathrm{BV}$ is performing intravaginal practices (IVP), in particular, intravaginal douching. ${ }^{3} 14 \quad 15$ IVP include introducing products inside the vagina for hygiene, health or sexuality reasons and can be divided into intravaginal cleansing or intravaginal insertion. ${ }^{16}$ IVP cause disruption of the vaginal flora facilitating $\mathrm{BV}$; and IVP are also associated with an increased risk of HIV acquisition. It has been postulated that IVP also increase the risk of HIV transmission by facilitating both $\mathrm{BV}$ and lower genital tract HIV shedding. ${ }^{15}$

Lower genital tract HIV shedding and HIV transmission occurs primarily in the presence of plasma viraemia, ${ }^{17-19}$ but reproductive tract infections such as BV could also facilitate lower genital HIV shedding and HIV transmission. ${ }^{20}{ }^{21}$ As most studies assessing HIV genital shedding have included women with detectable plasma viraemia, there is a need to evaluate HIV genital shedding as a potential marker of HIV transmission in women on suppressive antiretroviral therapy (ART).

Zambia is a sub-Saharan country with high rates of HIV infection. ${ }^{22}$ In Zambia, IVP are widely used and rates of BV are high. ${ }^{23}$ Little research in this country has been conducted to explore the relationship between IVP, BV and HIV lower genital shedding. The objective of this study is to describe types, frequencies and reasons for IVP, and to examine the relationship between IVP, BV and HIV shedding among women on ART, as a first step to understand how IVP and BV may increase HIV transmission. We hypothesised that frequent IVP would be associated with BV, and both IVP and BV would be associated with HIV lower genital shedding in women on ART.

\section{METHODS}

\section{Ethics statement}

Participants were provided with information about the study and assured of confidentiality of information and study records. Voluntary signed informed consent was obtained from all participants prior to participating in the study.

\section{Study design}

This study is a cross-sectional study. Participants completed audio computer-administered self-interview (ACASI) questionnaires assessing demographic and sexual risk factors, as well as frequency and types of IVP, and reasons for engaging in IVP; they also underwent vaginal examinations to assess BV and HIV lower genital shedding. Data presented are part of a larger study developing a culturally tailored intervention to decrease IVP and BV among HIV-1-infected women in Lusaka. Data presented in this cross-sectional analysis were obtained at baseline and prior to any participant receiving any study-related intervention. The study coordinator described IVP (intravaginal cleansing and intravaginal insertion) to the participants prior to completing the IVP questionnaire, and emphasised that IVP did not refer to external vaginal practices. Participants were recruited from May 2013 to February 2014. Study activities took place at a community health centre in urban Lusaka, Zambia. All audio and consent materials were provided in participants' preferred local languages (English, Bemba, Nyanja).

In order to develop questionnaires addressing IVP, focus groups, key informant interviews and introductory meetings with the clinic staff and local Community Advisory Boards were conducted at the community health centre; results have previously been described. ${ }^{24}$ Participants of the focus groups, key informants and members of the advisory boards, did not participate in the study. Participants were self-referred after hearing about the study from enrolled participants or clinic staff, and presented documentation of HIV-1 infection and treatment at the time of enrolment. Participants were HIV-1-infected women receiving antiretroviral medications and engaging in IVP in the month prior to enrolment, older than 18 years of age, sexually active, engaging in vaginal intercourse with men, not pregnant, not on contraceptive medications and not using an intrauterine device, and living in the Lusaka metropolitan area. The women underwent study assessment during the proliferative phase of the menstrual cycle (7-14 days after the first day of their menses). As IVP are widely used by Zambian women, all participants enrolled in the study had engaged in some type of IVP in the month prior to enrolment.

Participants underwent a $10 \mathrm{~mL}$ blood draw and vaginal examination. Genital samples collected were a vaginal swab collected from the mid-vaginal wall and cervicovaginal lavage (CVL). The vaginal swab was placed on a microscopy slide and analysed by Gram stain. Local clinic laboratory staff received training prior to reading the slides and the reading was performed by the same trained laboratory technician. In case of an unclear reading, the slide was reviewed by a second technician and the chief of the laboratory until an agreement was achieved. A didactic training session was conducted by the principal investigator at the laboratory site using a computer-based presentation and printed images. The principal investigator performed quality control by reviewing $20 \%$ of the slides at the clinic laboratory.

CVL was performed by instilling $10 \mathrm{cc}$ of sterile saline solution into the vaginal and cervical areas. Fluid was collected by aspiration after $60 \mathrm{~s}$. Blood and CVL samples were transported on ice to the laboratory for analysis. Analysis of RNA-1 viral load in blood and CVL was performed in fresh samples on arrival to the laboratory and within $2 \mathrm{~h}$ of collection.

\section{Demographics and sexual risk factors}

The demographic and sexual risk factors questionnaire was adapted by questionnaires previously used in similar settings by our group and included age, marital status, 
income, educational level, current partner HIV status, number of partners, sexual modalities (oral and anal sex), history of exchanging sex for money or gifts and use of condoms. ${ }^{2} 25$

\section{Medical history}

Medical history was self-reported. The medical history questionnaire included information on date of HIV infection, most current CD4 cells per millilitre, history of prior STIs (chlamydia, gonorrhoea, syphilis, trichomoniasis, genital herpes and genital warts) and history of prior episodes of BV. We did not perform CD4 count testing and did not collect data on ART regimens.

\section{Intravaginal practices}

The IVP questionnaire assessed specific products used for IVP, frequency of IVP and reasons for engaging in IVP. Products used for IVP and reasons for engaging in IVP were identified in the focus groups and key informant interviews. ${ }^{24}$ Questions to assess product used and reason for use in the prior month were on a dichotomous scale, 'yes' $=1$, 'no' $=0$; and each product was assessed individually. Frequency of each product was scored using 'daily' $=1$, 'weekly'=2 and 'monthly'=3, respectively. Products included: water alone, soap, a cloth rag or a sponge, herbs or flowers taken directly from the land, traditional medicines given by traditional healers, vinegar, salt, beer and yogurt. Reasons included: general hygiene, to get rid of a discharge, to remove blood after menses, to prevent pregnancy, to prevent STIs and to please sexual partner; responses to the reasons for engaging in IVP were not mutually exclusive. In order to assess frequency of IVP when different products were used, the number of women engaging in daily IVP was calculated by adding the number of women who answered yes to 'daily use' to any of the products; the number of women engaging in weekly IVP was calculated by adding the number of women who said yes to 'weekly use' and excluding those who endorsed daily IVP.

\section{Genital examination}

Detailed genital examination was performed in every participant by a qualified healthcare professional. Variables assessed included the presence of genital lesions (external, intravaginal or cervical), vaginal examination (vaginal discharge and characteristics), cervical examination (cervical discharge, ectopy, friability and tenderness), odour and $\mathrm{pH}$.

\section{Bacterial vaginosis}

BV was diagnosed using Nugent criteria (normal vaginal flora $=$ Nugent $0-3$; intermediate vaginal flora=Nugent 46 ; $\mathrm{BV}=$ Nugent $7-10$ ). Diagnosis of $\mathrm{BV}$ was made when the Nugent score was 7 or above.

\section{Plasma viraemia and HIV-1 lower genital shedding}

Plasma viraemia and HIV-1 genital shedding were assessed by measuring plasma and CVL HIV-1 RNA viral load, respectively, using an Abbott m2000 RealTime PCR system. CVL was aliquoted into Eppendorf tubes and directly used for determining viral load. Lower limit of detection was 40 copies $/ \mathrm{mL}$. Testing was conducted at Centre for Infectious Diseases Research in Zambia (CIDRZ) laboratories. Validation studies were performed to determine CVL viral load measures.

\section{Statistical analysis}

IBM SPSS Statistics for Windows V.21 (SPSS, Armonk, New York, USA) and SAS V.9.3 (SAS Institute, Inc, Cary, North Carolina, USA) were used for analysis. A sample of 128 women was calculated using $\mathrm{BV}$ as the primary outcome. Descriptive analyses were performed to describe demographic, medical and sexual risk factors, and IVP, BV and HIV-1 shedding. The dependent variables included (1) having the diagnosis of BV and (2) having HIV-1 RNA detectable in the CVL (HIV shedding). Independent variables included demographics, medical and sexual risk factor characteristics, and IVP. Bivariate prevalence ratios (PR) were calculated using a cross-tabulation of results; significance was assessed using a $95 \% \mathrm{CI}$ and $\mathrm{p}$ value was calculated using $\chi^{2}$ or Fischer's exact test. For statistically significant variables we then used a generalised linear model for a binary outcome with a $\log$ link to obtain the PR for a multivariable model. We report the PR and 95\% CIs. A p value of $<0.05$ was considered to be significant. Missing data were handled on a variable by variable basis. If the variable was missing, the case was eliminated for that analysis only. We did not impute data.

\section{RESULTS}

\section{Characteristics of study participants}

One hundred and twenty-eight HIV-1-infected participants receiving ART and engaging in IVP were enrolled. Median age was 37.3 years (range 24-60). The majority of participants had low education and an HIV-infected partner; and over one-third reported having other sexual partners in the prior month. Rates of reported oral sex, anal sex, history of exchanging sex for money and condom use were low. Most women had HIV infection for over 5 years and almost half self-reported having more than $500 \mathrm{CD} 4 \mathrm{~T}$ cells $/ \mathrm{mL}$. Sociodemographic characteristics, risk behaviours and medical characteristics of the study population are illustrated in table 1 .

\section{Genital examination}

Genital examination revealed no lesions in over $90 \%$ of participants. One participant had genital warts and one participant had ulcerations in the vagina. Vaginal secretions had a normal appearance in about $80 \%$ of participants and although participants did not report vaginal discharge, almost $20 \%$ of participants had a malodorous off-white/greyish thin discharge coating the vaginal walls. Cervical examination was normal in 120 participants (94.5\%), 6 participants had cervical ectopy and 2 
Table 1 Demographic, risk factors, medical history and IVP

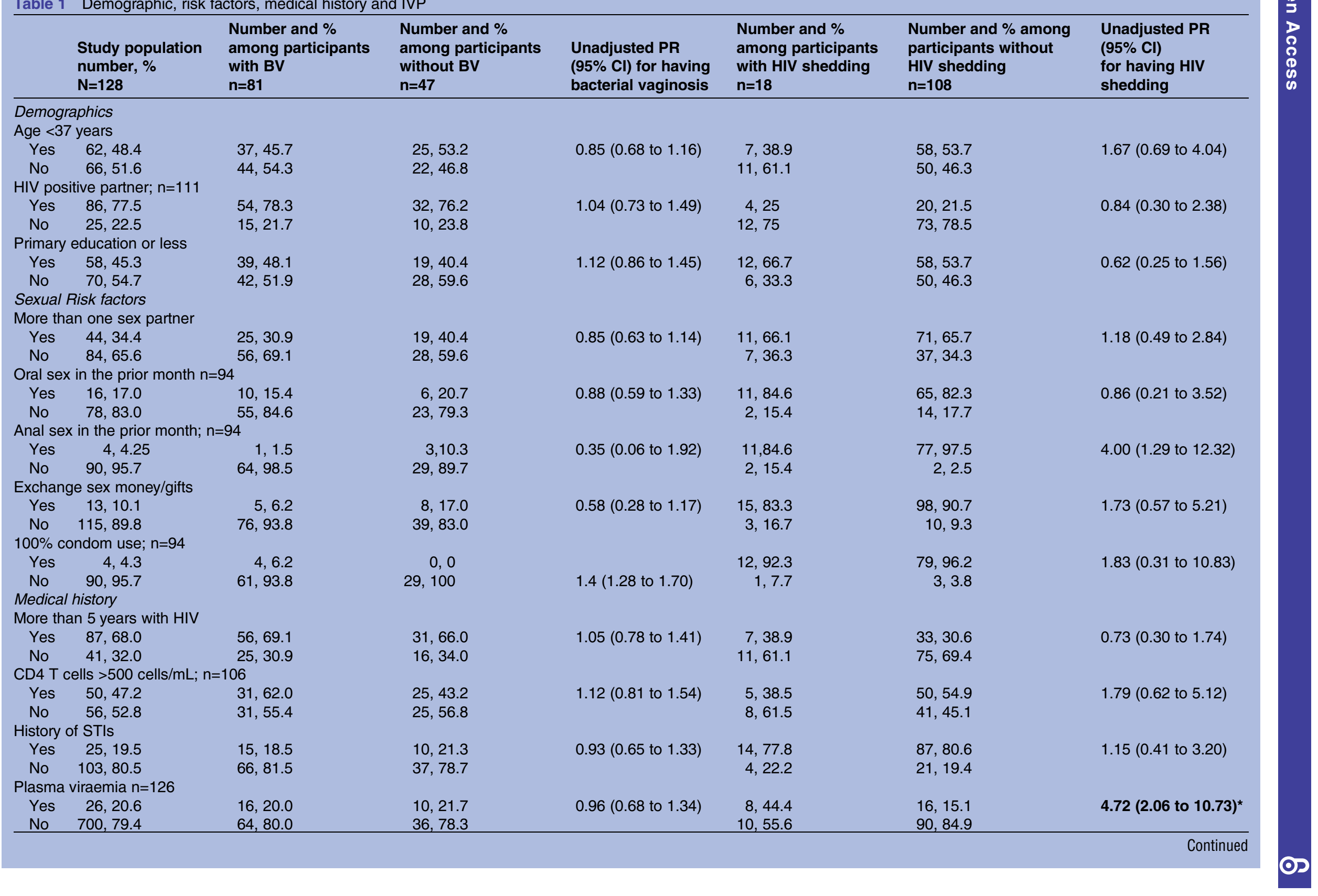




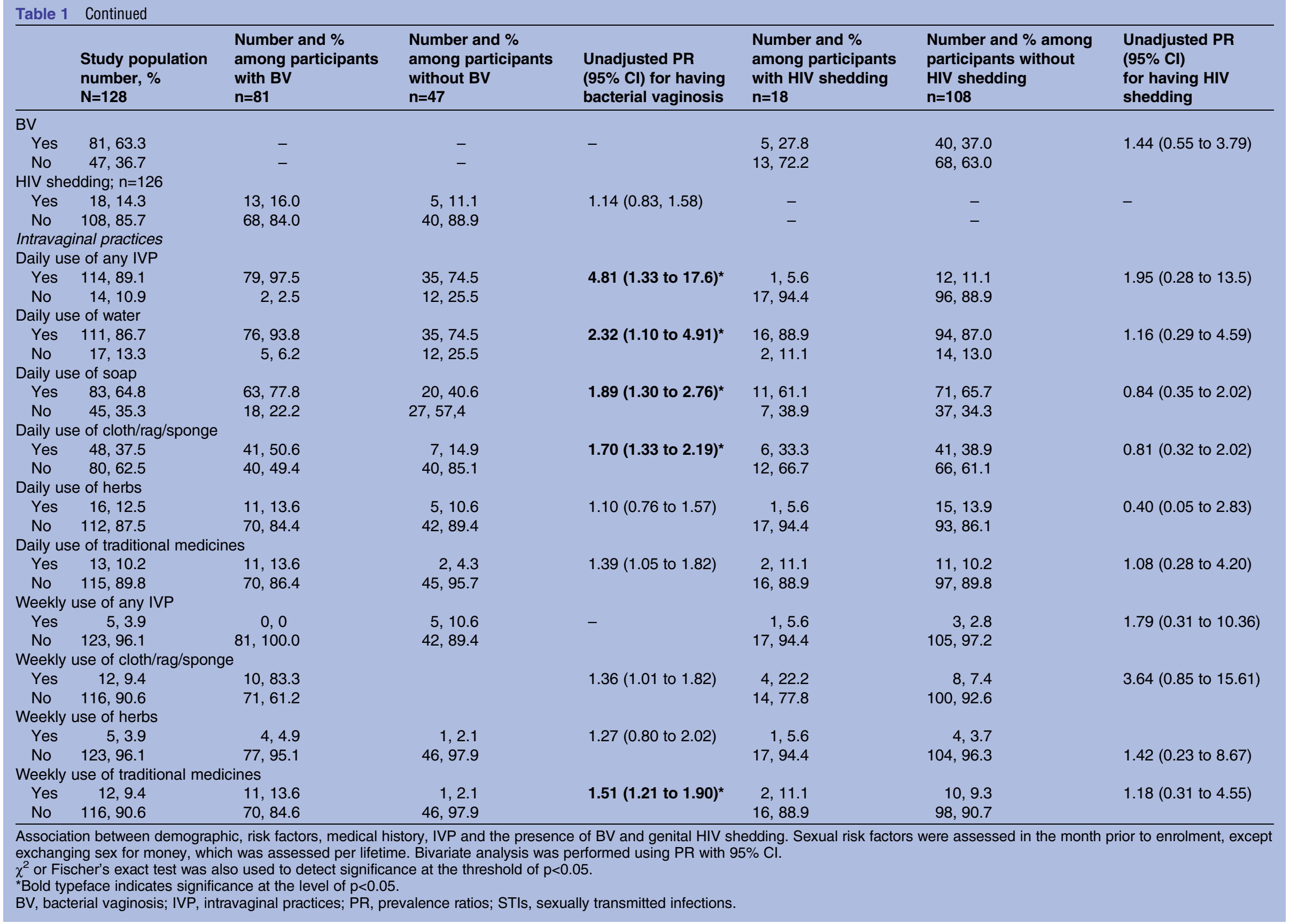


presented ulcerations. Normal vaginal $\mathrm{pH}$ (4.5 or less) occurred in only $6.7 \%$ of the participants; almost $80 \%$ of women had a vaginal $\mathrm{pH}$ over 5 . Cervical discharge and cervical tenderness was present in one participant (data not shown in table).

\section{Bacterial vaginosis}

Thirty participants $(23.5 \%)$ had normal vaginal flora (Nugent 0-3), 18 (14\%) had intermediate vaginal flora (Nugent 4-6) and $81(63.3 \%)$ had BV.

\section{HIV-1 viral load in plasma and cervicovaginal samples}

Twenty-six of 128 women (20.3\%) had detectable HIV-1 in plasma, $100(78.1 \%)$ had undetectable plasma viraemia and 2 had missing values. The median plasma viral load among those with a detectable level was 3.80 $\log _{10}$ copies/mL $(\mathrm{IQR}=2.13)$. Eighteen of 128 women (14.2\%) had detectable HIV-1 in cervicovaginal samples. The median CVL viral load among those with detectable level was $2.82 \log _{10}$ copies/mL (IQR=1.42).

Of the 100 women with undetectable HIV-1 in plasma, $8(8 \%)$ had HIV-1 lower genital shedding. The median CVL level in the eight women with undetectable plasma viral load and HIV-1 genital shedding was $2.32 \log _{10}$ copies $/ \mathrm{mL}$ (IQR=1.42) (not shown in table). Of these eight women, all engaged in daily IVP and seven had BV.

\section{Intravaginal practices}

Women reported engaging in IVP at a young age (median $=15$ years, range $8-41$ years). Most women had used IVP in the prior 2 days $(105,82 \%)$ and used IVP daily $(114,89 \%)$. Five women $(3.9 \%)$ reported using IVP only weekly and seven (5.5\%) used IVP monthly. Among different products used in the prior month, water had been used by 118 (92.2\%) women, soap by 88 $(68.7 \%)$, a cloth, rag or sponge by $68(53.1 \%)$, traditional medicines by $34(26.5 \%)$, and herbs and flowers from outdoors by $24(18.7 \%)$ women. Other products were vinegar $(4,3.1 \%)$, salt $(11,8.6 \%)$, beer $(8,6.3 \%)$ and lemon $(10,7.8 \%)$.

Different products were used for different reasons: water and soap were used for general hygiene (111, $86.7 \%$ and $84,65.6 \%$ of women respectively), followed by 'to get rid of a discharge or odour' $(36,28.1 \%$ for water and $36,28.1 \%$ for soap); a cloth (or rag or sponge) was used for general hygiene $(61,47.7 \%$ of women) followed by 'to please sexual partner' (33, $25.8 \%)$; traditional medicines were used for general hygiene $(24,18.7 \%)$ and to please sexual partners (24, $18.7 \%)$. Herbs and flowers collected from outside were used for general hygiene $(23,17.9 \%)$ and to please sexual partners $(13,10.1 \%)$. Participant's responses regarding the use of IVP are reported in table 2.

\section{Demographic, risk and IVP factors associated with BV}

The association of the different demographic and sexual risk factors, medical history and IVP, and the BV outcome is shown in table 1 . There was no evidence that demographic and sexual risk factors were associated with BV. Daily use of IVP with any product was associated with BV. Daily use of water, soap and cloth was associated with $\mathrm{BV}$; there was a strong relationship between the use of water, soap and cloth, suggesting that they are used together (not shown). Weekly use of IVP was also associated with $\mathrm{BV}$, in particular with the use of traditional medicines for IVP. Owing to the low number of women using weekly water or soap, the association of weekly use of these products and BV was not calculated. Vaginal examination with malodorous off-white or greyish thin discharge coating the vaginal walls and high $\mathrm{pH}$ (suggestive of BV) was not associated with the BV outcome (not shown).

Multivariable analysis with calculation of PR was performed adjusting for factors that showed a significant association in univariate analysis. ${ }^{13}$ Owing to the close relationship between daily use of the different components (cloth, soap and water), and to avoid collinearity, only daily use for IVP was included in the model. Weekly use of traditional medicines was included in the model since it was strongly associated with BV. In the multivariable model, daily use of IVP and weekly use of traditional medicines was associated with having BV (table 3).

\section{Demographic, risk and IVP factors associated with HIV-1 genital shedding}

The association of the different demographic, sexual risk factors, medical history and IVP, and the HIV-1 genital shedding outcome, is shown in table 1 . The only variable associated with lower genital HIV shedding was plasma viraemia. Multivariable analysis adjusted for daily use of IVP, BV and plasma viraemia was performed, and plasma viraemia was the only variable associated with HIV-1 shedding (table 3). Exploratory analyses were performed in women with undetectable HIV-1 plasma viral load to examine the relationship of the demographic and sexual risk factors, and medical history, including BV and IVP, with HIV-1 genital shedding. There was no significant association with sociodemographics, risk factors, medical history and BV, with HIV-1 genital shedding in women with undetectable HIV-1 plasma viral load (results not shown).

\section{DISCUSSION}

This study sought to clarify the relationship between IVP, $\mathrm{BV}$ and HIV lower genital shedding among women engaging in IVP in Zambia, as a first step in understanding if IVP affects HIV transmission in women on ART. We found that daily use of IVP and weekly use of traditional medicines were associated with $\mathrm{BV}$; the only factor associated with HIV genital shedding was HIV plasma viraemia. Neither IVP nor BV were associated with lower genital HIV shedding in this study.

Studies addressing IVP in women in sub-Saharan Africa have primarily involved the HIV-uninfected 
Table 2 Participant's responses regarding IVP $(\mathrm{N}=128)$

Participant's Responses Regarding Intravaginal Practices Age of IVP initiation in years, range 15.8 years, $8-41$

Recency of IVP In the last 2 days

2 days to 1 week

1-2 weeks

2 weeks to 1 month

Frequency of IVP (any product)

Daily

Weekly

Monthly

Products used for IVP in the prior

month and frequency of use

Water

Recency, in the last 2 days

Frequency

Daily

Weekly

Monthly

Reason

For general female hygiene

To get rid of a discharge/odour

To remove blood after menses

To prevent pregnancy

To prevent STIS

Soap

23, 17.9

$88,68.7$

$87,67.9$

$83,64.8$

2, 1.6

$3,2.3$

$84,65.6$

$36,28.1$

29, 22.6

$8,6.2$

0,0

$16,12.5$

$68,53.1$

$60,46.8$

$48,37.5$

$12,9.3$

$8,6.2$

Reason

For general female hygiene

To get rid of a discharge/odour

To remove blood after menses

To prevent pregnancy

To prevent STIs

To please sexual partner

Traditional medicines

Recency, in the last 2 days

Frequency

Daily

Weekly

Monthly
$61,47.7$

23, 18

$18,14.1$

$3,2.3$

0,0

$33,25.8$

$34,26.5$

25, 19.5

$13,10.1$

$12,9.4$

$9,7.0$
Table 2 Continued

Reason

For general female hygiene

To get rid of a discharge/odour

$24,18.7$

To remove blood after menses

$5,3.9$

To prevent pregnancy

$6,4.7$

To prevent STls

To please sexual partner

$2,1.6$

0,0

$24,18.7$

Herbs and flowers from outdoors

$24,18.7$

Recency, in the last 2 days

22, 17.1

Frequency

Daily

Weekly

$16,12.5$

Monthly

$5,3.9$

$3,2.3$

Reason

For general female hygiene $\quad 23,17.9$

To get rid of a discharge/odour

$5,3.9$

To remove blood after menses

$4,3.1$

To prevent pregnancy

$1,0.8$

To prevent STIS

0,0

To please sexual partner

$13,10.1$

Products listed are those that were used by more than $10 \%$ of the participants. Other products assessed and used by $<10 \%$ of participants were vinegar, salt, beer and yogurt.

IVP, intravaginal practices; STIs. sexually transmitted infections.

population and have shown a significant association of IVP with BV; and of both IVP and BV with HIV acquisi-

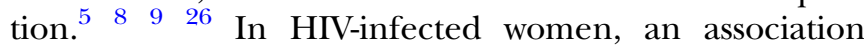
between BV and HIV lower genital shedding, and BV and in utero HIV transmission, has been described. ${ }^{10}$ This may suggest an increase in HIV transmission in women with BV, but this study further describes the relationship between IVP, BV and HIV shedding in HIV-infected women on ART. ${ }^{27} 28$

HIV lower genital shedding is responsible for HIV transmission, and viral suppression and treatment as prevention is one of the pillars of HIV prevention programmes in developed and in developing countries. ${ }^{17} 1829{ }^{30}$ However, it has been proposed that local factors such as STIs or BV, may increase HIV transmission and lower genital shedding in studies including untreated HIV women and adjusted for plasma viraemia. ${ }^{15} 212731$ Our study confirms that the primary factor associated with HIV genital shedding is plasma viraemia, and if viraemia is suppressed with the use of ART, transmission is likely to be suppressed. However, our study did not find an association between BV and HIV lower genital shedding as previously found by others ${ }^{21}$ and this is likely due to the low number of women with detectable plasma viraemia. Our results support effective ART as the main strategy to prevent HIV-1 female genital shedding, and subsequent HIV transmission.

In our study, we confirmed that rates of BV among women engaging in IVP in Zambia are very high, and women use IVP frequently for reasons of hygiene and sexuality. Prior studies in sub-Saharan Africa have also noted rates of BV being around $40-50 \%$, and higher in 
Table 3 Multivariable analysis of factors associated with having BV or HIV-1 genital shedding

\begin{tabular}{|c|c|c|}
\hline & $\begin{array}{l}\text { Adjusted PR }(95 \% \text { Cl) for } \\
\text { having BV }\end{array}$ & p Value \\
\hline $\begin{array}{l}\text { More than one } \\
\text { sex partner }\end{array}$ & $1.01(0.76$ to 1.34$)$ & 0.952 \\
\hline $\begin{array}{l}\text { Exchange sex for } \\
\text { money/gifts }\end{array}$ & 0.64 (0.32 to 1.26$)$ & 0.195 \\
\hline Daily use of IVP & $4.58(1.26 \text { to } 16.64)^{*}$ & $0.021^{\star}$ \\
\hline \multirow{2}{*}{$\begin{array}{l}\text { Weekly use of } \\
\text { traditional } \\
\text { medicines for IVP }\end{array}$} & $1.33(1.05 \text { to } 1.68)^{\star}$ & $0.020^{\star}$ \\
\hline & $\begin{array}{l}\text { Adjusted PR }(95 \% \mathrm{Cl}) \text { for } \\
\text { having HIV shedding }\end{array}$ & p Value \\
\hline Plasma viraemia & $4.61(2.02 \text { to } 10.54)^{\star}$ & $0.001^{*}$ \\
\hline Daily use of IVP & $1.29(0.18$ to 9.27$)$ & 0.803 \\
\hline BV & 1.32 (0.51 to 3.38$)$ & 0.567 \\
\hline \multicolumn{3}{|c|}{$\begin{array}{l}\text { *Bold typeface indicates significance at the level of } p<0.05 \text {. } \\
\mathrm{PR}, 95 \% \mathrm{Cl} \text { and } \mathrm{p} \text { value. Model for the outcome BV was adjusted } \\
\text { for having more than one sex partner, having history of } \\
\text { exchanging sex for money, daily use of IVP and weekly use of } \\
\text { traditional medicines. Model of the outcome HIV shedding was } \\
\text { adjusted for plasma viraemia, daily use of IVP and BV. } \\
\text { BV, bacterial vaginosis; IVP, intravaginal practices; PR, } \\
\text { prevalence ratio. }\end{array}$} \\
\hline
\end{tabular}

women with HIV. ${ }^{2} 332$ Additionally, we confirmed that most cases of BV are asymptomatic. This is important to note as most BV cases would likely be missed in sub-Saharan settings where syndromic management is the norm. Since IVP are very prevalent in this population, finding a group of women not engaging in IVP appeared to be impossible, and we chose to evaluate if different frequency and products used for IVP were associated with $\mathrm{BV}^{2}{ }^{33}$ We found a strong relationship between daily use of IVP and BV. The aetiology of BV remains unknown and controversy exists regarding whether BV is caused by a sexually transmitted pathogen or not. While some studies suggest a strong association with sexual practices and IVP, in particular vaginal douching, ${ }^{3} 1415$ sexual transmission of $\mathrm{BV}$ and that the causative organism is Gardnerella vaginalis have also been proposed. ${ }^{11} 12 \mathrm{BV}$ and other STI share similar risk factors such as unprotected vaginal intercourse, new sexual partners and recurrence after treatment. However, in our study, we did not find an association of BV with demographic or sexual risk factors and daily use of IVP was the main factor associated with BV. In addition, we found that weekly use of traditional medicines was associated with $\mathrm{BV}$, and traditional medicines were used by one-quarter of the participants. It is not clear why more frequent use of traditional medicines was not associated with BV, but, as previously reported, traditional medicines are used for hygiene, health ('to get rid of a discharge') or to facilitate 'dry sex'. ${ }^{24}$ We postulate that different products are used with different frequencies and cause different mucosal changes that could facilitate BV. Further studies addressing additional risk factors, including male partners, expanding mucosal studies and including analysis of the vaginal microbiome, will help in understanding the biological relationship between IVP, mucosal damage and BV.

The study results must be interpreted within certain limitations: (1) given the high rates of daily IVP and the low rates of HIV shedding, the sample size may have limited the ability to detect associations; (2) the information collected on HIV risk behaviours, medical history and IVP, was self-reported, though the social desirability bias may have been decreased by using ACASI-administered questionnaires, a useful tool for assessment of high-risk behaviours in African settings ${ }^{34}$ (3) this is a cross-sectional study and the direction of causality cannot be determined; (4) based on the lower rates reported in our prior studies, we did not assess the use of other products (orally ingested or externally applied) that may have an effect on vaginal mucosa; (5) STI testing was not performed and the presence of STI could have an effect on HIV shedding, though we previously found low rates of STI in this population; ${ }^{35}$ (6) exposure to semen was not assessed and (7) our results may not be generalisable to other sub-Saharan countries where IVP may be different.

In summary, this study addresses an extremely important area in the field of women's health in sub-Saharan Africa, the relationship between IVP, BV and HIV shedding, and study outcomes highlight important reasons for IVP interventions. Our results indicate that effective ART remains the main strategy to prevent HIV female genital shedding and subsequent HIV transmission. These findings support early initiation of ART as an HIV prevention tool and support the need for additional studies to further assess causality in the associations between IVP and BV in ART-treated women, as well as for studies assessing culturally tailored interventions to decrease $\mathrm{BV}$ in high-prevalence settings.

\section{Author affiliations}

${ }^{1}$ Division of Infectious Diseases, University of Miami, Miller School of Medicine, Miami, Florida, USA

${ }^{2}$ University of Zambia, University Teaching Hospital, Lusaka, Zambia ${ }^{3}$ Department of Epidemiology and Public Health, University of Miami, Miller School of Medicine, Miami, Florida, USA

${ }^{4}$ Department of Psychiatry and Behavioral Sciences, University of Miami, Miller School of Medicine, Miami, Florida, USA

Acknowledgements The authors would like to thank all those in our research team at the University Teaching Hospital in Lusaka. They also thank the community sites providing referrals and the women participating in this study.

Contributors All the authors have seen and approved the content of this manuscript, have contributed significantly to the work and declare no conflict of interest. No writing assistance was sought in preparing this manuscript. MLA, DLJ, MF and MC contributed to the conception and design of the work. MLA and EM contributed to the acquisition of the data. MLA and KA contributed to the analysis and interpretation of the data. MLA and DLJ drafted the work and all the authors revised it critically for important intellectual content.

Funding This study was funded by a grant from the National Institute of Health (K23HD074489). The Miami Center for AIDS Research (CFAR) at the University of Miami Miller School of Medicine (P30AI073961) provided mentorship and statistical support. 
Competing interests None declared.

\section{Patient consent Obtained.}

Ethics approval Institutional review board (University of Miami Miller School of Medicine) and research ethics committee (University of Zambia) approvals were obtained prior to recruitment and any assessment or study-related procedures.

Provenance and peer review Not commissioned; externally peer reviewed.

Data sharing statement No additional data are available.

Open Access This is an Open Access article distributed in accordance with the Creative Commons Attribution Non Commercial (CC BY-NC 4.0) license, which permits others to distribute, remix, adapt, build upon this work noncommercially, and license their derivative works on different terms, provided the original work is properly cited and the use is non-commercial. See: http:// creativecommons.org/licenses/by-nc/4.0/

\section{REFERENCES}

1. Holmes KK, Sparling PF, Stamm WE, et al. Sexually transmitted diseases. 4th edn. New York: McGraw-Hill, 2008.

2. Alcaide ML, Mumbi M, Chitalu N, et al. Vaginal cleansing practices in HIV infected Zambian women. AIDS Behavior 2013;17: 872-8.

3. Fonck K, Kaul R, Keli F, et al. Sexually transmitted infections and vaginal douching in a population of female sex workers in Nairobi, Kenya. Sex Transm Infect 2001;77:271-5.

4. Bloom BS, Lee DW. Bacterial vaginosis and preterm birth. $N$ Engl J Med 1996;334:1338-9.

5. Taha TE, Hoover DR, Dallabetta GA, et al. Bacterial vaginosis and disturbances of vaginal flora: association with increased acquisition of HIV. AIDS 1998;12:1699-706.

6. Atashili J, Poole C, Ndumbe PM, et al. Bacterial vaginosis and HIV acquisition: a meta-analysis of published studies. AIDS 2008:22:1493-501.

7. Cohen CR, Duerr A, Pruithithada N, et al. Bacterial vaginosis and HIV seroprevalence among female commercial sex workers in Chiang Mai, Thailand. AIDS 1995;9:1093-7.

8. Hilber AM, Francis SC, Chersich M, et al. Intravaginal practices, vaginal infections and HIV acquisition: systematic review and meta-analysis. PLOS ONE 2010;5:e9119.

9. Low N, Chersich MF, Schmidlin K, et al. Intravaginal practices, bacterial vaginosis, and HIV infection in women: individual participant data meta-analysis. PLoS Med 2011;8:e1000416.

10. Farquhar C, Mbori-Ngacha D, Overbaugh J, et al. Illness during pregnancy and bacterial vaginosis are associated with in-utero HIV-1 transmission. AIDS 2010;24:153-5.

11. Muzny CA, Schwebke JR. Suspected heterosexual transmission of bacterial vaginosis without seminal fluid exposure. Sex Transm Dis 2014;41:58-60.

12. Klebanoff MA, Andrews WW, Zhang J, et al. Race of male sex partners and occurrence of bacterial vaginosis. Sex Transm Dis 2010;37:184-90.

13. Fethers KA, Fairley CK, Hocking JS, et al. Sexual risk factors and bacterial vaginosis: a systematic review and meta-analysis. Clin Infect Dis 2008;47:1426-35.

14. Brotman RM, Klebanoff MA, Nansel TR, et al. A longitudinal study of vaginal douching and bacterial vaginosis-a marginal structural modeling analysis. Am J Epidemiol 2008;168:188-96.

15. Clark RA, Theall KP, Amedee AM, et al. Frequent douching and clinical outcomes among HIV-infected women. Sex Transm Dis 2007:34:985-90.
16. Martin Hilber A, Hull TH, Preston-Whyte E, et al. A cross cultural study of vaginal practices and sexuality: implications for sexual health. Soc Sci Med 2010;70:392-400.

17. Reynolds SJ, Makumbi F, Nakigozi G, et al. HIV-1 transmission among HIV-1 discordant couples before and after the introduction of antiretroviral therapy. AIDS 2011;25:473-7.

18. Quinn TC, Wawer MJ, Sewankambo N, et al. Viral load and heterosexual transmission of human immunodeficiency virus type 1. Rakai Project Study Group. N Engl J Med 2000;342:921-9.

19. Gray $\mathrm{RH}$, Wawer MJ, Brookmeyer R, et al. Probability of HIV-1 transmission per coital act in monogamous, heterosexual, HIV-1-discordant couples in Rakai, Uganda. Lancet 2001;357:1149-53.

20. Cohen CR, Lingappa JR, Baeten JM, et al. Bacterial vaginosis associated with increased risk of female-to-male HIV-1 transmission: a prospective cohort analysis among African couples. PLoS Med 2012;9:e1001251.

21. Low AJ, Konate I, Nagot N, et al. Cervicovaginal HIV-1 shedding in women taking antiretroviral therapy in Burkina Faso: a longitudinal study. J Acquir Immune Defic Syndr 2014;65:237-45.

22. Minister of Health Z. Zambia Country Report. Secondary Zambia Country Report. 2012. http://www.unaids.org/en/dataanalysis/ knowyourresponse/countryprogressreports/2012countries/ce_ZM_ Narrative_Report.pdf

23. Mbikusita-Lewanika M, Stephen $H$, Thomas J. The prevalence of the use of 'dry sex' traditional medicines, among Zambian women, and the profile of the users. Psychol Health Med 2009;14:227-38.

24. Alcaide ML, Chisembele M, Mumbi M, et al. Examining targets for HIV prevention: intravaginal practices in Urban Lusaka, Zambia. AIDS Patient Care STDS 2014;28:121-7.

25. Jones DL, Weiss SM, Bhat GJ, et al. Influencing sexual practices among HIV-positive Zambian women. AIDS Care 2006;18:629-34.

26. McClelland RS, Lavreys L, Hassan WM, et al. Vaginal washing and increased risk of HIV-1 acquisition among African women: a 10-year prospective study. AIDS 2006;20:269-73.

27. Fastring DR, Amedee A, Gatski M, et al. Co-occurrence of Trichomonas vaginalis and bacterial vaginosis and vaginal shedding of HIV-1 RNA. Sex Transm Dis 2014;41:173-9.

28. Cu-Uvin S, Hogan JW, Caliendo AM, et al. Association between bacterial vaginosis and expression of human immunodeficiency virus type 1 RNA in the female genital tract. Clin Infect Dis 2001;33:894-6.

29. Ioannidis JP, Abrams EJ, Ammann A, et al. Perinatal transmission of human immunodeficiency virus type 1 by pregnant women with RNA virus loads <1000 copies/ml. J Infect Dis 2001;183: 539-45.

30. Cohen MS, Chen YQ, McCauley M, et al. Prevention of HIV-1 infection with early antiretroviral therapy. $N$ Engl J Med 2011;365:493-505.

31. Tanton C, Weiss HA, Le Goff J, et al. Correlates of HIV-1 genital shedding in Tanzanian women. PLOS ONE 2011;6:e17480.

32. van de Wijgert $\mathrm{JH}$, Chirenje ZM, Iliff $\mathrm{V}$, et al Effect of intravagina practices on the vaginal and cervical mucosa of Zimbabwean women. J Acquir Immune Defic Syndr 2000;24:62-7.

33. Hull T, Hilber AM, Chersich MF, et al. Prevalence, motivations, and adverse effects of vaginal practices in Africa and Asia: findings from a multicountry household survey. J Womens Health (Larchmt) 2011;20:1097-109.

34. van der Elst EM, Okuku HS, Nakamya $P$, et al. Is audio computer-assisted self-interview (ACASI) useful in risk behaviour assessment of female and male sex workers, Mombasa, Kenya? PLOS ONE 2009;4:e5340.

35. Alcaide ML, Jones DL, Chitalu N, et al. Chlamydia and Gonorrhea Infections in HIV-positive Women in Urban Lusaka, Zambia. J Glob Infect Dis 2012:4:141-4. 